\title{
Obesity increases the risk of incident asthma among adults
}

\author{
E. Rönmark**,\#, C. Andersson ${ }^{+}$, L. Nyström ${ }^{\S}$ B. Forsberg ${ }^{+, f}$, B. Järvholm ${ }^{\dagger}$ and B. Lundbäck*,\#
}

\begin{abstract}
The annual incidence of asthma in adults in northern Sweden has been estimated at 2.3 per thousand population. Risk factors for incident asthma among adults were studied in a case-referent study based on incident cases of asthma during 1995-1999.

The healthcare providers reported suspected cases of incident asthma. After clinical examination, 309 (65\% female) of 473 reported subjects were included. Inclusion criteria were a history of incident asthma (onset $<12$ months) and verified bronchial variability. Referents were randomly selected and stratified by age, sex and area of residence.

The significant risk factors were hay fever, a family history of asthma, ex-smoking status and elevated body mass index $(25.0-29.9$ and $\geqslant 30)$. The risk factor pattern was similar for females and males, and increased body mass index was a significant risk factor for both males and females, as well as for allergic and nonallergic subjects.

In conclusion, in addition to hay fever, a family history of asthma, allergic sensitisation and exsmoking status, increased body mass index was a significant risk factor for incident asthma independent of sex and allergic status.
\end{abstract}

KEYWORDS: Adults, epidemiology, incident asthma, obesity

$\mathbf{T}$ he prevalence of asthma has increased worldwide since the 1960s [1, 2]. The incidence of asthma is highest among children [3-5]. However, the annual incidence of asthma is also relatively high among adults and has, in northern Sweden, been estimated at 2.3 per thousand population [6].

Studies of risk factors for adult asthma have mainly analysed case-referent or cross-sectional design data based on prevalent cases of asthma [7]. Such studies may determine either cause, consequence or both. Incidence studies have mostly focused on occupational asthma [8] or smoking habits $[6,9,10]$.

Since the late 1990s, obesity has been reported to be associated with asthma [11-13], and an increase in the prevalence of obesity in Western society has been reported along with a parallel increase in asthma prevalence [14]. However, CHINN and RONA [15] have suggested that the increase in asthma prevalence cannot be explained by the increased prevalence of obesity in the population. Further, obesity may be a consequence of asthma. A convincing relationship between asthma and obesity has not been established. Three prospective studies have found obesity or an increased body mass index (BMI) to be associated with new onset of asthma among females [13, 16, 17]. In another study, pre-teenage overweight preceded asthma and bronchial hyperreactivity in female children [18]. In contrast, a recent study found obesity to be significantly related to incident asthma only among male and nonallergic children [19].

Within the Obstructive Lung Disease in Northern Sweden (OLIN) studies, a case-referent study was designed to identify risk factors for adult incident asthma with the main focus on the environment. In the first phase of the study, obesity as a risk factor for asthma was studied.

All citizens aged 20-60 yrs living in three municipalities (Luleå, Piteå and Boden) in the northernmost province of Sweden, Norrbotten, comprised the study base (fig. 1). From September 1995 to December 1999, suspected incident cases of asthma were reported from primary healthcare, hospitals, private clinics and occupational health physicians. The patients had contacted the healthcare providers due to respiratory problems. The reported cases were examined by the OLIN group.

\section{Study area}

Luleå and Piteå are located on the Baltic Sea coast, whereas Boden is located $40 \mathrm{~km}$ inland. Luleå is the administrative, commercial and cultural centre of the province, and has the

\section{MATERIALS AND METHODS}

AFFILIATIONS

*The Obstructive Lung Diseases in Northern Sweden Studies, Dept of Medicine, Sunderby Central Hospital of Norrbotten, Luleå, and

\#Lung and Allergy Research, National Institute of Environmental Medicine, Karolinska Institutet, Stockholm, and Dept of Public Health and Clinical Medicine, Divisions of

"Respiratory Medicine and Allergy,

${ }^{\S}$ Epidemiology, and

${ }^{f} 0$ ccupational and Environmental

Medicine, and

${ }^{+}$Dept of Environmental Health

Sciences, University of Umeå, Umeå,

Sweden.

CORRESPONDENCE

E. Rönmark

The OLIN Studies

Stadsvikens vårdcentral

Robertsviksgatan 9

SE-971 89 Luleå

Sweden

Fax: 46920230843

E-mail: eva.ronmark@nll.se

Received:

May 062004

Accepted after revision:

September 222004

SUPPORT STATEMENT

This study was supported by the Swedish Council for Working Life, Stockholm, the Centre for Environmental Research, Umeå, the Swedish Foundation for Health Care Science and Allergy Research

(Vårdal), Stockholm, and the Swedish Heart-Lung Foundation, Stockholm, Sweden.

European Respiratory Journal Print ISSN 0903-1936

Online ISSN 1399-3003 


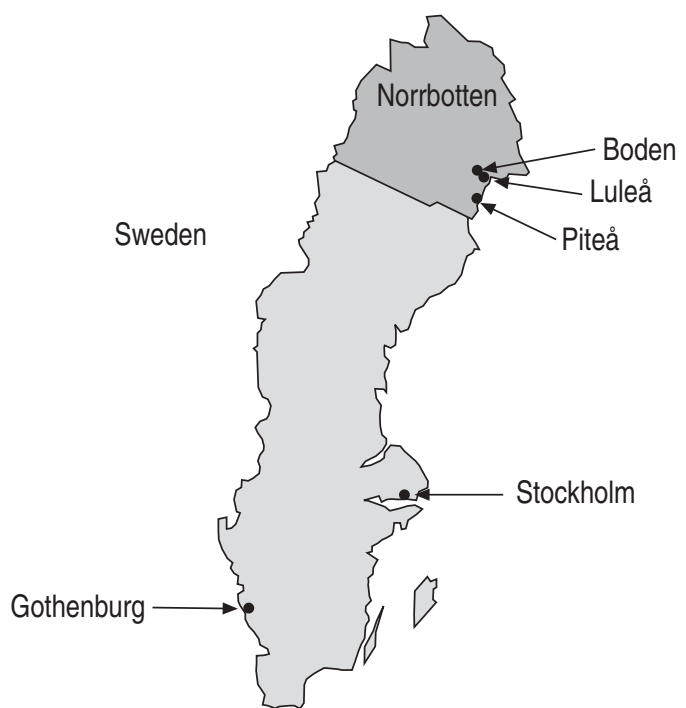

FIGURE 1. Map showing study areas.

largest steel industry in Sweden. Luleå had 70,694 inhabitants in 1994, of which 40,970 were aged 20-60 yrs. Piteå had 21,797 inhabitants in this age range, and a high concentration of wood and paper pulp industries. The central hospital of Norrbotten was located in Boden at the time of the study, and the town has several military units. Boden had 15,903 inhabitants aged 20-60 yrs.

\section{Selection of cases and referents}

The reported cases of suspected incident asthma were contacted over the telephone for a short interview and to make an appointment for a medical examination. A total of 54 subjects were not invited to the examinations as they obviously did not fulfil the inclusion criteria for incident asthma, or did not want to participate (fig. 2). The examination included a structured interview, lung function test, methacholine test and skin-prick test. A reversibility test, or measurements of morning and evening peak expiratory flow (PEF), was performed in subjects in whom a contraindication for

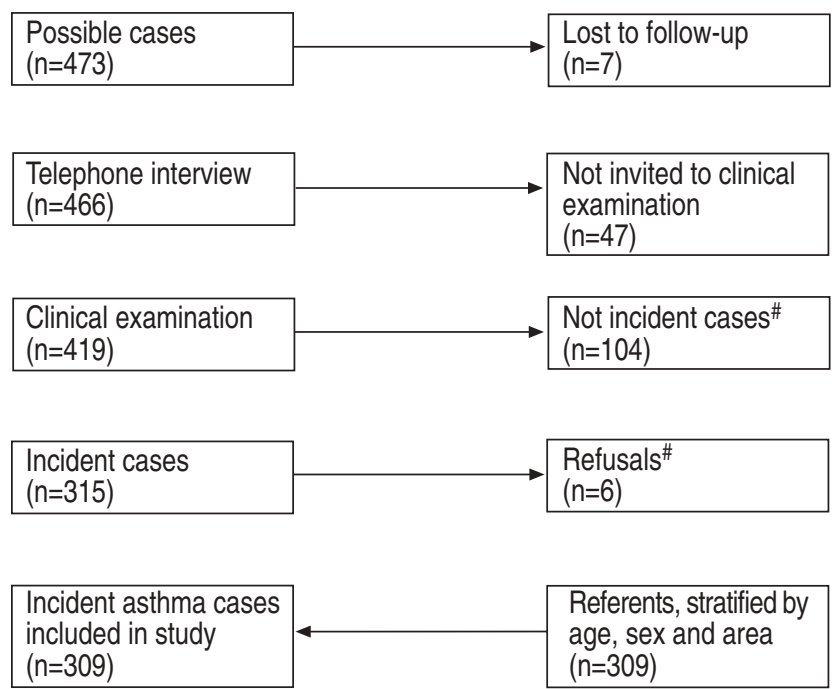

FIGURE 2. Study design. \#: see table 1 .

methacholine testing existed, i.e. pregnancy or lactation, suspected ischaemic heart disease, use of $\beta$-receptor-blocking pharmaceuticals or a forced expiratory volume in one second (FEV1) of $<65 \%$ of the predicted value. Further, in subjects with negative methacholine test results, a reversibility test or registration of PEF was performed. Four specially trained nurses conducted the examinations.

Of the 419 subjects invited to the clinical examinations, 315 fulfilled the inclusion criteria, and 309 agreed to participate. The main reasons for exclusion were onset of asthma earlier than within the last 12 months, and that asthma probably existed but the inclusion criteria were not fulfilled (table 1).

For each case, four possible referents of the same sex born on the same day, or the day before or after, who were living in the same municipality were randomly selected from the Swedish register of the general population. The first contacted subject who agreed to participate was included. The referents were also contacted over the telephone and invited to an examination including structured interview, lung function test and

TABLE 1 Cases examined, included and not included in the study, and reasons for exclusion by sex and age

\begin{tabular}{|c|c|c|c|c|c|c|c|}
\hline & \multicolumn{2}{|c|}{ Sex } & \multicolumn{4}{|c|}{ Age yrs } & \multirow[t]{2}{*}{ Total } \\
\hline & Male & Female & 19-29 & $30-39$ & $40-49$ & $50-60$ & \\
\hline Examined cases $\mathbf{n}$ & 153 & 266 & 128 & 123 & 109 & 59 & 419 \\
\hline Included cases $\mathbf{n}$ & 107 & 202 & 89 & 94 & 81 & 45 & 309 \\
\hline Excluded cases $n$ & 46 & 64 & 39 & 29 & 28 & 14 & 110 \\
\hline \multicolumn{8}{|l|}{ Reason for exclusion $\mathbf{n}$} \\
\hline Probable asthma, but inclusion criteria not fulfilled & 9 & 26 & 16 & 7 & 10 & 2 & 35 \\
\hline Asthma, but debut $>12$ months ago & 17 & 18 & 13 & 11 & 6 & 5 & 35 \\
\hline Chronic bronchitis or COPD & 2 & 3 & 0 & 1 & 2 & 2 & 5 \\
\hline Not obstructive lung disease & 16 & 13 & 7 & 9 & 9 & 4 & 29 \\
\hline Asthma, but could not or did not want to participate & 2 & 4 & 3 & 1 & 1 & 1 & 6 \\
\hline
\end{tabular}

COPD: chronic obstructive pulmonary disease 
skin-prick test. Of 449 contacted referents, 43 were excluded due to asthma, whereas 97 did not want to participate.

Subjects with asthma in childhood were excluded both as cases and referents.

\section{Structured interview}

The interview questionnaire included questions from the OLIN questionnaire [6], the International Union Against Tuberculosis and Lung Disease questionnaire [20] and the interview questionnaire developed for the European Community Respiratory Health Survey [21]. Questions about dyspnoea in general, cough and phlegm were included, with the aim of differentiating between asthma and chronic obstructive pulmonary disease. In addition, questions about family history of asthma and allergy, hay fever, eczema, smoking habits and childhood factors were included.

\section{Skin-prick test}

The skin-prick tests were performed on the volar aspect of one forearm as single tests with allergen in 50\% glycerol, using a lancet with a 1-mm tip. The allergens used were cat, dog, horse, birch, timothy grass, mugwort, Dermatophagoides farinae, D. pteronyssinus, Cladosporium and Alternaria (Soluprick; ALK, Hørsholm, Denmark). A positive reaction was recorded if the diameter of the weal was $\geqslant 3 \mathrm{~mm}$ after $15 \mathrm{~min}$.

\section{Lung function test}

The lung function tests were performed following American Thoracic Society recommendations [22] and using a dry spirometer. Swedish reference values were used [23]. For PEF measurements, a Mini-Wright peak flow meter (Clement Clarke International, Harlow, UK) was used. Morning and evening PEF were recorded before taking any bronchial dilator.

\section{Methacholine tests}

Methacholine tests were performed using an Aiolos ondemand nebuliser with an electricity-driven compressor and a controlled output (Aiolos Medicinsk Teknik, Karlstad, Sweden). Methacholine chloride was used at concentrations of $0.1,0.25,0.5,1,2,4,8$ and $16 \mathrm{mg} \cdot \mathrm{mL}^{-1}$. Provocative concentrations of methacholine causing a $20 \%$ fall in FEV1 (PC20) were calculated from the FEV1 measured after inhalation of isotonic sodium chloride solution. The method was calibrated against that described by JUNIPER et al. [24].

\section{Inclusion criteria for cases}

The inclusion criteria were based on clinical examinations performed by the OLIN group. They included a history of asthma with an onset within the last 12 months and a physiological test verifying bronchial variability.

At least four of the following criteria had to be fulfilled: 1) wheezing or whistling in the chest; 2) attacks or periods of shortness of breath; 3) no symptoms between the attacks or periods; 4) at least two provoking factors with the exception of "common cold" and "physical exertion"; and 5) at least two attacks or periods since onset of symptoms.

Bronchial variability was present if at least one of the following was fulfilled: 1) a positive methacholine test, defined as a PC20 of $\left.<8 \mathrm{mg} \cdot \mathrm{mL}^{-1} ; 2\right)$ a positive reversibility test, defined as an increase in FEV1 of $\geqslant 15 \%$, or an increase in FEV1 of $\geqslant 10 \%$ in combination with an increase in forced vital capacity of $\geqslant 20 \%$ after inhalation of $0.8 \mathrm{mg}$ Ventolin ${ }^{\circledR}$ administrated by metereddose or powdered-dose inhaler; and 3) a positive PEF curve, defined by $\geqslant 3$ days with a difference between morning and evening PEF of $\geqslant 15 \%$ during a 2 -week period, $\geqslant 20 \%$ difference on $\geqslant 2$ days during the 2 -week period, $\geqslant 25 \%$ difference between the highest and second lowest PEF during a 7 -day period, or $\geqslant 30 \%$ difference between the highest and second lowest PEF during a 14-day period.

\section{Inclusion criteria for referents}

Since subjects with asthma were excluded from being referents, none of the following were allowed to be present: a diagnosis of asthma made by a physician, a history of asthma, or any previous use of asthma medicines.

\section{Definitions}

A family history of asthma was defined as asthma among the father, mother or a sibling. Subjects were defined as smokers if they smoked every week or had stopped smoking within the preceding 12 months. Those who had stopped smoking $>12$ months prior to the study were classified as ex-smokers. Hay fever was defined as a report of past or present hay fever, and eczema as a report of past or present eczema. The BMI was defined as the weight in kilograms divided by the height in metres squared $\left(\mathrm{kg} \cdot \mathrm{m}^{-2}\right)$. Pets at home during childhood was defined as having pets at home before the age of 7 yrs. Respiratory infection during childhood was defined as a report of severe respiratory infection before the age of $7 \mathrm{yrs}$. A positive skin-prick test was defined as having a weal of $\geqslant 3 \mathrm{~mm}$ in response to any of the tested allergens.

\section{Statistical methods}

Comparisons of proportions were tested using the Chi-squared test. Continuous data are expressed in mean $\pm \mathrm{SD}$, and comparisons of means were tested using an unpaired t-test. A p-value of $<0.05$ was regarded as significant. Multiple logistic regression analyses were performed using the independent variables that were significantly associated with incident asthma in the bivariate analyses, presenting the results as odds ratio (OR) (95\% confidence interval (CI)). The independent variables included in the model were study area, age, sex, smoking habit, BMI, eczema, hay fever, family history of asthma and the skin-prick test result.

\section{RESULTS}

The mean $\pm S D$ age of the subjects was $37 \pm 10.6$ yrs. The 309 cases, $65 \%$ of which were female, correspond to an annual incidence of new-onset asthma of 1.3 per thousand population. Adding the cases with probable asthma, although not fulfilling the present criteria for incident asthma, the annual incidence was 1.8 per thousand population. The annual incidence based on all 473 reported cases was 2.0 per thousand population.

\section{Characteristics of incident cases}

Bronchial variability was verified by methacholine test in 284 of the 309 cases, positive reversibility test in 11 and peak flow curve in nine. In five subjects, bronchial variability was not verified during the examination, but they had documented bronchial variability from a test performed before the referral. Three of them were already receiving maintenance treatment with 
inhaled corticosteroids, and methacholine test performance was contraindicated in three of the five subjects. Among the 309 cases, wheezing was reported by $90 \%$, attacks of shortness of breath by $99 \%$, and all 309 subjects reported some provoking factors. Most common were respiratory infections, strong scents, cold air, physical exertion, and allergens from pets or pollen.

Mean FEV1 (\% pred) among the cases was significantly lower than among the referents ( 92.2 versus $99.2 \% ; \mathrm{p}<0.001)$. There was no association between FEV1 (\% pred) and BMI among cases or referents.

\section{Bivariate analyses of risk factors for incident asthma}

Eczema, hay fever, a positive skin-prick test result and a family history of asthma were all more prevalent among cases compared to referents, resulting in significantly increased ORs (1.6, 5.5, 2.1 and 2.2, respectively; table 2). Also exsmokers exhibited a significantly increased risk of asthma (OR 1.6 (95\% CI 1.1-2.3); table 2).

The mean BMI was significantly higher among cases than referents, among both females $(25.3 \pm 5.1$ versus $23.6 \pm 3.9$; $\mathrm{p}<0.001)$ and males $(26.6 \pm 3.3$ versus $25.5 \pm 3.6 ; \mathrm{p}=0.015)$. A $\mathrm{BMI}$ of $\geqslant 25$ was associated with a significantly increased risk of asthma (table 2).

Asthma was related to elevated BMI among allergic as well as nonallergic subjects. Among subjects with a positive skin-prick test result, mean BMI among asthmatics was $25.8 \pm 4.3$ versus $23.7 \pm 3.7$ among referents $(\mathrm{p}<0.001)$. Corresponding values among nonsensitised individuals were $25.7 \pm 4.8$ versus $24.4 \pm 4.0(\mathrm{p}=0.005)$.

The frequency of severe respiratory infection or pets at home during childhood did not differ between cases and referents (table 2).

\section{Multivariate relationships}

The risk factor pattern observed in the bivariate analyses was confirmed by the multivariate analyses. The most important risk factor for incident asthma was hay fever (OR 4.8 (95\% CI 3.0-7.8)), whereas a positive skin-prick test result was not significantly related to incident asthma in the multivariate model. Except for a family history of asthma, which increased the risk more for males than females, there were no differences between the sexes. Furthermore, ex-smoking status was a significant risk factor (OR 1.6 (95\% CI 1.1-2.5); table 3).

Increased BMI was also a significant risk factor in the multivariate analyses, yielding an OR (95\% CI) of 2.0 (1.33.1) for a BMI of 25.0-29.9, and $2.7(1.5-4.7)$ for a BMI of $\geqslant 30$. Increased BMI was a significant risk factor for incident asthma among both males and females, as well as among sensitised and nonsensitised subjects (table 3). No interaction was found between BMI and ex-smoking status or any of the other risk factors.

When the independent variables hay fever and eczema were excluded from the model, the variable positive skin-prick test became a significant risk factor (OR 2.3 (95\% CI 1.6-3.2)), whereas the estimates of risk for other variables included in the model remained unchanged.

An increase in the specificity of the variables airway hyperreactivity and positive skin-prick test did not change the results. When the 49 asthmatics with a PC20 of $4.0-8.0 \mathrm{mg} \cdot \mathrm{mL}^{-1}$ were excluded from the analyses, the results for all of the variables were almost identical. The same was true if a cut-off of $5 \mathrm{~mm}$ was chosen for the definition of a positive skin-prick test result. Although the prevalence decreased to $29.9 \%$ among the cases, and to $14.0 \%$ among the referents, the results of the risk factor analyses did not change.

\section{TABLE 2 Basic characteristics of cases and referents}

\begin{tabular}{|c|c|c|c|c|}
\hline Variable & Cases & Referents & OR $(95 \% \mathrm{Cl})$ & p-value \\
\hline Positive skin-prick test & 44.1 & 27.0 & $2.1(1.5-3.0)$ & $<0.001$ \\
\hline Hay fever & 40.5 & 11.0 & $5.5(3.5-8.6)$ & $<0.001$ \\
\hline Eczema & 34.6 & 25.3 & $1.6(1.1-2.3)$ & 0.012 \\
\hline \multicolumn{5}{|l|}{ Smoking habit } \\
\hline Smoker & 21.1 & 25.3 & $0.9(0.6-1.4)$ & \\
\hline \multicolumn{5}{|l|}{ BMI } \\
\hline$<20$ & 8.1 & 10.1 & $1.0(0.6-1.9)$ & \\
\hline 20-24.9 & 42.1 & 55.0 & 1 & 0.002 \\
\hline $25-29.9$ & 33.7 & 25.7 & $1.7(1.2-2.5)$ & \\
\hline$\geqslant 30$ & 16.2 & 9.1 & $2.3(1.4-3.9)$ & \\
\hline Mean FEV $1 /$ VC & $0.80(0.47-0.97)$ & $0.81(0.41-0.98)$ & & 0.038 \\
\hline
\end{tabular}

Data are presented as percentages or mean (range), unless otherwise stated. OR: odds ratio; Cl: confidence interval; BMI: body mass index (kg. $\left.\mathrm{m}^{-2}\right)$; FEV1: forced expiratory volume in one second; \% pred: percentage of the predicted value; VC: vital capacity. 
TABLE 3 Multiple logistic regression analysis of risk factors for incident asthma

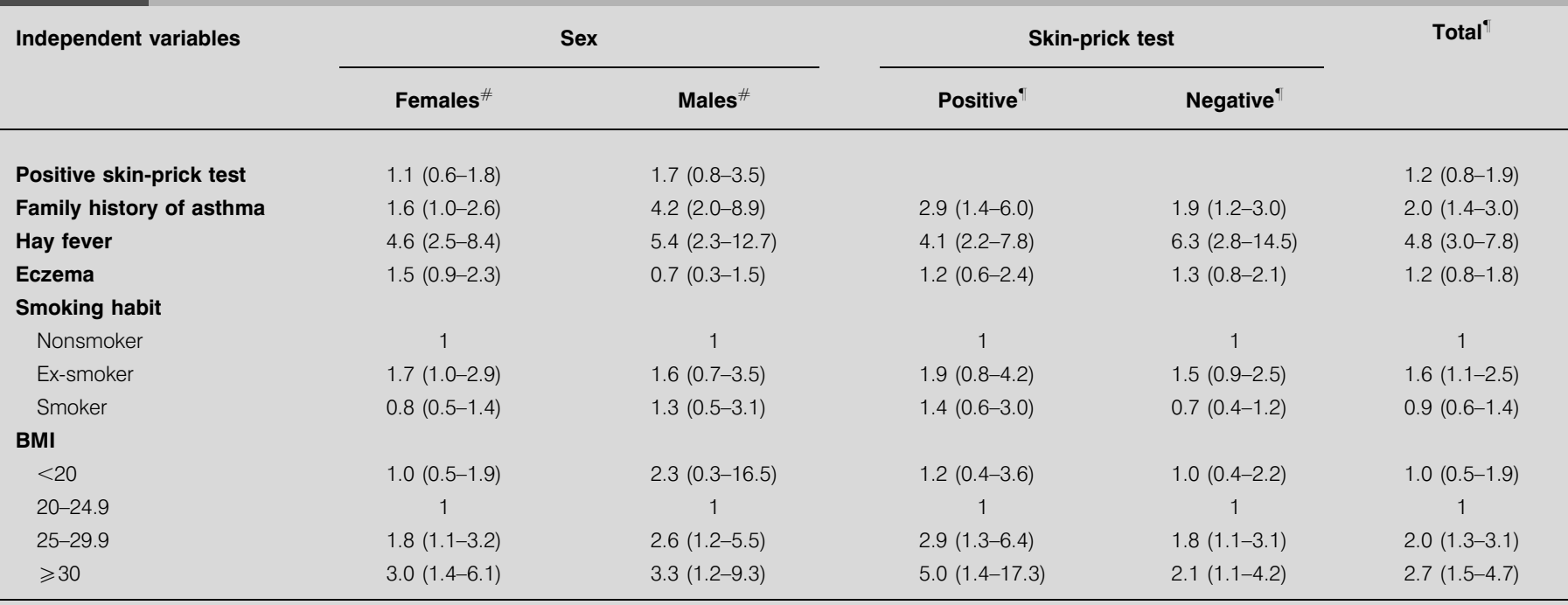

Data are presented as odds ratio (95\% confidence interval). BMI: body mass index $\left(\mathrm{kg} \cdot \mathrm{m}^{-2}\right) .{ }^{\#}$ : adjusted for area and age; ${ }^{\circ}$ : adjusted for area, age and sex.

\section{DISCUSSION}

The results of the present study indicate that obesity is a significant risk factor for the development of asthma in adulthood among both females and males. Furthermore, this relationship was also found among subjects with both positive and negative skin-prick test results.

When selecting cases for a study of risk factors, the specificity of the diagnosis of the disease is crucial. Thus, a rigorous selection procedure was employed for the incident cases. First, the subjects were examined by a physician, most often a general practitioner (GP), and then reported as presumed cases of incident asthma. Secondly, at the examination performed by the OLIN group, both a history of asthma and a physiological test showing bronchial variability were required. A total of 35 cases were labelled as probable asthma but not included as they did not fulfil the strict criteria of the study. Thirdly, subjects who had had asthma in childhood or a history of symptoms common in asthma $>12$ months prior to the referral were excluded. Of the contacted referents, 9.6\% had asthma and were thus excluded. The prevalence of asthma among the referents is a good reflection of the prevalence in the general population in the study area [2]. The high participation rate among both cases and controls supports the validity of the results.

The number of reported cases of incident asthma from GPs and others was 473 , which corresponds to an annual incidence of 2.0 per thousand population. This result is very close to the annual incidence of 2.3 per thousand population based on repeated self-completed postal questionnaires sent to the general population in the area during the same time period [6]. In that study, a subsample was validated by methacholine tests and clinical examination. The small difference in incidence may be due to differences in methods and some missing reports from GPs and others. Some of the reported incident cases had had symptoms common in asthma $>12$ months prior to the study, or had had childhood asthma. Of the remaining subjects, corresponding to an annual incidence of 1.8 per thousand population, several subjects did not fulfil the strict study criteria for incident asthma. As the aim was to optimise for high specificity and not have false positives among the cases, the subjects included in the study analyses corresponded to an annual incidence of asthma of 1.3 per thousand population. The sex distribution of the incident cases of asthma was similar to those found in results from population studies $[6,10]$.

Parallel increases in the prevalence of asthma and in obesity have been reported in affluent countries, and an association between obesity and asthma has recently been observed among both children [25, 26] and adults [11, 12]. The associations are not consistent, since one study reported an association between obesity and asthma or wheezing, but not airway hyperresponsiveness, which is closely associated with asthma [12]. Furthermore, increased BMI has mostly been associated with asthma among females. Recent studies among adults, two of them prospective, found an association between obesity and asthma among females but not among males [11, $16,17]$, and a prospective study among young females found an association between obesity and the incidence of asthma [13]. In addition, among children, only a few prospective studies have studied the association between obesity or BMI and the development of asthma. In one study, the relationship was found among female children [18], whereas it was only significant among male children in another large study in southern California, USA [19].

The pathophysiology behind the link between asthma and increased BMI is not clear. There are several possible contributory mechanisms, which have recently been reviewed [27]. The association may be indirectly related due to reflux or a higher intrathoracic pressure on the airways, or through a parallel effect due to lifestyle factors, such as diet, lack of physical activity or socio-economic factors [15]. Recently, metabolic mechanisms have been discussed. Obesity and metabolic syndrome are related to insulin resistance, which, 
in turn, is also related to impaired lung function among males [28]. In addition, it has been suggested that obesity acts through nonallergic mechanisms in the development of asthma, as the association has more often been found among nonsensitised subjects $[19,26]$. The present results indicate that the effect may be mediated by the mechanical pressure of the respiratory airways rather than by hormonal or allergic inflammation of the airways, since the association was found among females and males, as well as sensitised and nonsensitised subjects.

Hay fever is closely related to and may often precede asthma. In cross-sectional studies of adults from the same area [2], hay fever has yielded similar or even greater ORs than in the present study. Notably, $40 \%$ of the incident cases of asthma reported hay fever. In studies based on prevalent cases, the proportion of asthmatics with rhinitis or hay fever is even greater $[2,29]$.

Allergic sensitisation was a significant risk factor for incident adult asthma only in the bivariate model. In the multivariate model, this relationship was found only when other diseases related to sensitisation were not included in the analyses. These results identify the very high-risk population, i.e. the symptomatic among the sensitised.

A family history of asthma was a significant risk factor, as reported in other studies of asthma in similar $[5,6]$ and other populations $[3,30]$. However, the association between a family history of asthma and incident asthma in the present study was weaker than that described in other studies, among children $[5,30]$ and adults $[2,6]$. Further, a family history of asthma and a positive skin-prick test result had less influence on the risk of asthma among females compared with males. This may indicate a bias due to a difference between males and females in reporting family history, or represent a true difference in risks or asthma phenotypes in males and females.

The association between asthma and smoking is unclear. Several studies have shown smoking at any time or exsmoking status to be associated with asthma [9, 31]. Some incidence studies among teenagers or young adults $[3,32]$ and adults $[6,10]$ have shown current smoking to be related to incident asthma, whereas others have not [33]. In crosssectional studies, and in case-control studies also based on prevalent cases, it is not clear whether or not the subjects experienced their onset of asthma before or after they had stopped smoking. Bias of that kind was avoided in the present study, as the onset of asthma had occurred within the last 12 months, and those who had stopped smoking during this same time period were classified as current smokers. Thus, the present study found only ex-smoking status to be a significant risk factor for asthma. Owing to the present definitions of both incident asthma and smoking habits, it is unlikely that the relationship reflects only smoking cessation due to asthma.

In conclusion, a high body mass index increased the risk of development of asthma in adults. This effect was independent of hormonal and allergic status, since the association between asthma and elevated body mass index was found in both females and males, and among sensitised and nonsensitised subjects. However, there is a need for further studies to elucidate the pathogenesis of incident asthma.

\section{ACKNOWLEDGEMENTS}

The authors would like to thank A-C. Jonsson, K. Östling and I. Nes for collection of the data, and M. Mattsson and T. Andersson for data management. The GPs are acknowledged for referral of asthmatics.

\section{REFERENCES}

1 Woolcock AJ, Peat JK. Evidence for the increase in asthma worldwide. Ciba Found Symp 1997; 206: 122-134.

2 Lundbäck B. Epidemiology of rhinitis and asthma. Clin Exp Allergy 1998; 28: 3-10.

3 Strachan DP, Butland BK, Anderson HR. Incidence and prognosis of asthma and wheezing illness from early childhood to age 33 in a national British cohort. BMJ 1996; 312: 1195-1199.

4 Yunginger JW, Reed CE, O'Connell EJ, Melton LJ, O'Fallon WM, Silverstein MD. A community based study of the epidemiology of asthma. Incidence rates, 1964-1983. Am Rev Respir Dis 1992; 146: 888-894.

5 Rönmark E, Perzanowski MS, Platts-Mills T, Lundbäck B. Incidence rates and risk factors for asthma among school children: a 2-year follow-up report from the Obstructive Lung Disease in Northern Sweden (OLIN) studies. Respir Med 2002; 96: 1006-1013.

6 Lundbäck B, Rönmark E, Jönsson E, Larsson K, Sandström T. Incidence of physician-diagnosed asthma in adults: a real incidence or a result of increased awareness? Report from the Obstructive Lung Disease in Northern Sweden studies. Respir Med 2001; 95: 685-692.

7 Torén K, Balder B, Brisman J, et al. The risk of asthma in relation to occupational exposure: a case-control study from a Swedish city. Eur Respir J 1999; 13: 496-501.

8 Karjalainen A, Kurppa K, Martikainen R, Karjalainen J, Klaukka T. Exploration of asthma risk by occupation: extended analysis of an incidence study of the Finnish population. Scand J Work Environ Health 2002; 28: 49-57.

9 Flodin U, Jönsson P, Ziegler J, Axelson O. An epidemiologic study of bronchial asthma and smoking. Epidemiology 1995; 6: 503-505.

10 Torén K, Hermansson BA. Incidence rate of adult-onset asthma in relation to age, sex, atopy and smoking. A Swedish population-based study of 15813 adults. Int J Tuberc Lung Dis 1999; 3: 192-197.

11 Shaheen SO, Sterna JA, Montgomery SM, Azima H. Birthweight, body mass index and asthma in young adults. Thorax 1999; 54: 396-402.

12 Schachter LM, Salome CM, Peat JK, Woolcock AJ. Obesity is a risk factor for asthma and wheeze but not for airway hyperresponsiveness. Thorax 2001; 56: 4-8.

13 Camargo CA Jr, Weiss ST, Zhang S, et al. Prospective study of body mass index, weight change, and risk of adult-onset asthma in women. Arch Intern Med 1999; 159: 2582-2588.

14 World Health Organization. Obesity: preventing and managing the global epidemic. Report of a WHO Consultation on Obesity. Geveva, World Health Organization, 1997.

15 Chinn S, Rona RJ. Can the increase in body mass index explain the rising trend in asthma in children? Thorax 2001; 56: 845-850.

16 Chen Y, Dales R, Tang M, Krewski D. Obesity may increase the incidence of asthma in women but not in men: longitudinal observations from the Canadian National 
Population Health Surveys. Am J Epidemiol 2002; 155: 191-197.

17 Beckett WS, Jacobs DR Jr, Yu X, et al. Asthma is associated with weight gain in females but not males, independent of physical activity. Am J Respir Crit Care Med 2001; 164: 2045-2050.

18 Castro-Rodriguez JA, Holberg CJ, Morgan WJ, Wright AL, Martinez FD. Increased incidence of asthma like symptoms in girls who become overweight or obese during the school years. Am J Respir Crit Care Med 2001; 163: 1344-1349.

19 Gilliland FD, Berhane K, Islam T, et al. Obesity and the risk of newly diagnosed asthma in school-age children. Am J Epidemiol 2003; 158: 406-415.

20 Burney PG, Laitinen LA, Perdrizet S, et al. Validity and repeatability of the IUATLD (1984) Bronchial Symptoms Questionnaire: an international comparison. Eur Respir J 1989; 2: 940-945.

21 Burney PG, Luczynska CM, Chinn S, Jarvis D. The European Community Respiratory Health Survey. Eur Respir J 1994; 7: 954-960.

22 American Thoracic Society. ATS statement. Snowbird workshop on standardization of spirometry. Am Rev Respir Dis 1979; 119: 831-838.

23 Berglund E, Birath G, Grimby G, Kjellmer I, Sandqwist L, Söderholm B. Spirometric studies in normal subjects. Forced expirograms in subjects between 7 and 70 years of age. Acta Med Scand 1963; 173: 185-192.

24 Juniper E, Frith P, Dunnett C, Cockcroft D, Hargreave F. Reproducibility and comparison of responses to inhaled histamine and methacholine. Thorax 1978; 33: 705-710.
25 Somerville SM, Rona RJ, Chinn S. Obesity and respiratory symptoms in primary school. Arch Dis Child 1984; 59: 940-944.

26 von Mutius E, Schwartz J, Neas LM, Dockery D, Weiss ST. Relation of body mass index to asthma and atopy in children: the National Health and Nutrition Examination Study III. Thorax 2001; 56: 835-838.

27 Jubber AS. Respiratory complications of obesity. Int J Clin Pract 2004; 58: 573-580.

28 Lazarus R, Sparrow D, Weiss ST. Impaired ventilatory function and elevated insulin levels in nondiabetic males: the Normative Aging Study. Eur Respir J 1998; 12: 635-640.

29 Björnsson E, Plaschke P, Norrman E, et al. Symptoms related to asthma and chronic bronchitis in three areas of Sweden. Eur Respir J 1994; 7: 2146-2153.

30 Forsberg B, Pekkanen J, Clench-Aas J, et al. Childhood asthma in four regions in Scandinavia: risk factors and avoidance effects. Int J Epidemiol 1997; 26: 610-619.

31 Vesterinen E, Kaprio J, Koskenvou M. Prospective study of asthma in relation to smoking habits among 14, 729 adults. Thorax 1988; 43: 534-539.

32 Larsson L. Incidence of asthma in Swedish teenagers: relation to sex and smoking habits. Thorax 1995; 50: 260-264.

33 Troisi RJ, Speizer FE, Rosner B, Trichopoulus D, Willett WC. Cigarette smoking and incidence of chronic bronchitis and asthma in women. Chest 1995; 108: 1557-1561. 